Document downloaded from:

http://hdl.handle.net/10251/49129

This paper must be cited as:

Trujillo Rodríguez, CL.; Velasco De La Fuente, D.; Figueres Amorós, E.; Garcerá Sanfeliú, G.; Ortega, R. (2011). Modeling and control of a push-pull converter for photovoltaic microinverters operating in island mode. Applied Energy. 88(8):2824-2834.

doi:10.1016/j.apenergy.2011.01.053.

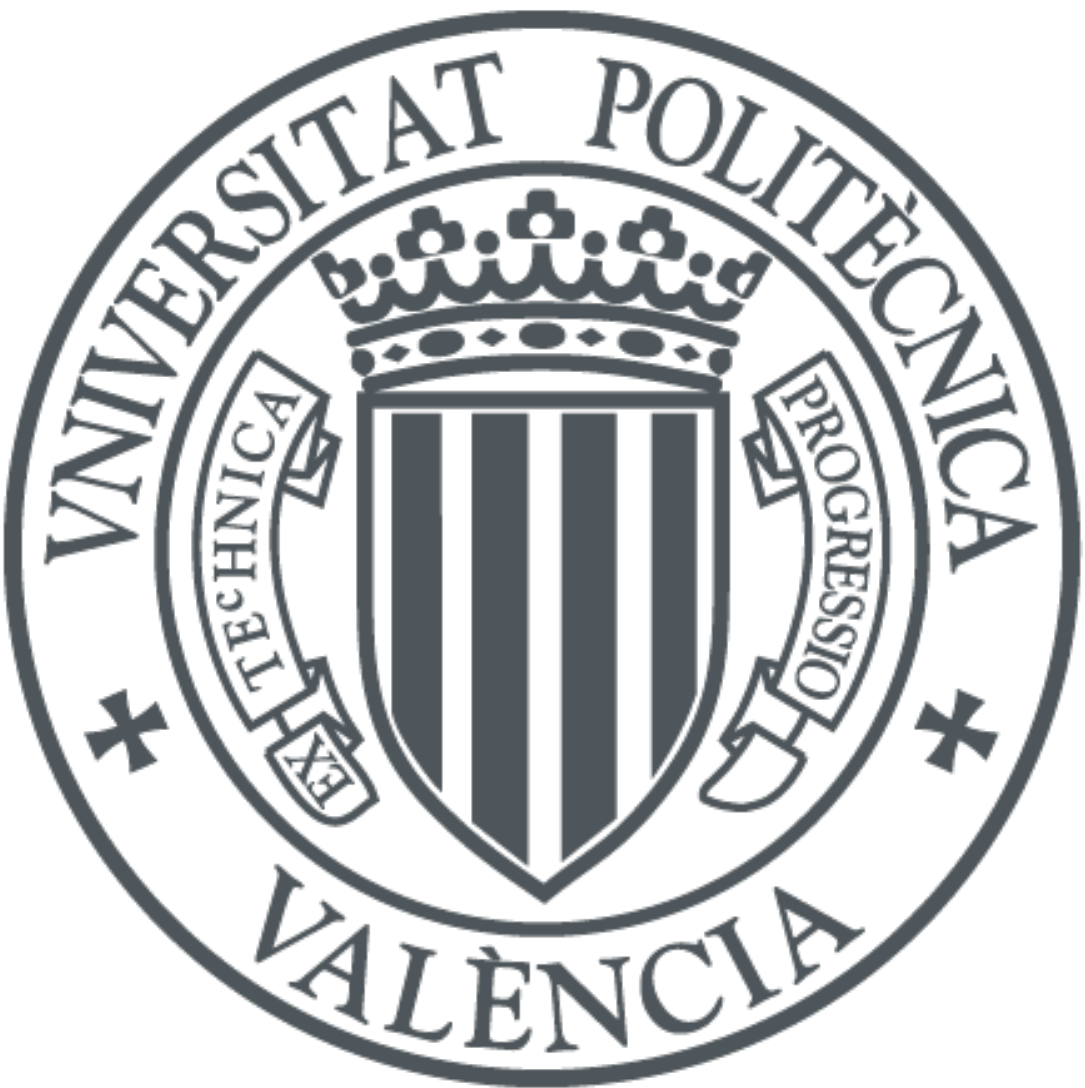

The final publication is available at

http://dx.doi.org/10.1016/j.apenergy.2011.01.053

Copyright Elsevier

Additional Information 


\title{
Modeling and control of a Push-Pull converter for photovoltaic microinverters operating in island mode
}

\author{
C.L. Trujillo ${ }^{1,2}$, D. Velasco ${ }^{1}$, E. Figueres ${ }^{1}$, G. Garcerá ${ }^{1}$, R. Ortega ${ }^{1,3}$ \\ ${ }^{1}$ Grupo de Sistemas Electrónicos Industriales del Departamento de Ingeniería Electrónica, \\ Universidad Politécnica de Valencia, Camino de Vera S/N, C.P. 46022, Valencia, Spain, \\ http://www.gsei.upv.es, e-mail: davede@posgrado.upv.es, efiguere@eln.upv.es, ggarcera@eln.upv.es \\ ${ }^{2}$ Departamento de Ingeniería Electrónica, Universidad Distrital Francisco José de Caldas, Carrera 7 \\ No 40-53 Piso 5, Bogotá, Colombia, e-mail: cltrujillo@udistrital.edu.co \\ ${ }^{3}$ Escuela Superior de Cómputo - Instituto Politécnico Nacional, Av. Juan de Dios Bátiz S/N, D. F., \\ 07738, México, e-mail: rortegag@ipn.mx
}

\begin{abstract}
This paper presents the modeling and control of a push-pull converter integrated into a twostage photovoltaic microinverter operating in island mode without backup energy storage components (batteries). A push-pull small signal model is presented, from which they are derived all transfer functions needed to implement the controllers that regulate the output current, input voltage and output voltage interacting with the MPPT algorithm. A significant contribution of the paper is the proposal of an innovative control structure that simultaneously regulates in island mode both the ac voltage and the dc voltage of the panels, in order to place it in the best operation point. Such operation point is calculated by a specific control loop that interacts with the MPPT algorithm. To validate the proposed concept, simulations in $\mathrm{PSIM}^{\mathrm{TM}}$ were carried out.
\end{abstract}

Keywords: Distributed Generation, Microinverters, Photovoltaics Panels, Push-pull.

\section{Introduction}

In recent years, a major global priority is the development of renewable energy. These energy sources produce lower pollution in terms of $\mathrm{CO} 2$ emissions than conventional fossil fuels. From this point of view the distributed generation concept takes importance and it represents a paradigm shift from centralized power generation [1-2].

Distributed generation can be defined as small-scale generators installed near the loads with the ability of interacting with the grid importing or exporting energy [3].

Under this scheme, autonomous low power converters called microinverters [4] have been developed. Microinverters have the ability of operating both in grid connected mode by injecting energy from renewable sources (solar energy, wind energy, fuel cells, among others) to the grid, and in islanding mode feeding local loads without grid connection. Besides, they can be connected to other inverters with similar characteristics to supply a higher number of loads, being easy to expand [5-6].

Since photovoltaic (PV) panels supply a too low voltage to directly inject power to the grid by means of an inverter, microinverters working from a single PV panel normally use a twostage power topology composed by a DC/DC converter providing a high enough DC voltage to a grid connected inverter. In a $230 \mathrm{Vac}$ single-phase grid the DC voltage provided to the inverter is usually $380 \mathrm{Vdc}$ to $400 \mathrm{Vdc}$. 
The proposed microinverter is composed by a push-pull DC/DC converter that processes the energy generated by the panels, feeding a single-phase power inverter that injects the energy into the grid if the microinverter is operating in grid mode, or feeds local loads if it is working in island mode. This topology is a good choice for low input voltage and medium power. Its advantage when compared to Full-bridge DC-DC converters is that only two power transistors are needed. When compared to a Half-bridge DC-DC converter, the Push-pull doesn't need a capacitive input voltage divider bearing high RMS currents. The main drawback of the Push-pull topology is that the power transistors withstand twice the input voltage, but that is not a problem in low input voltage applications.

This paper focuses on the operation of the push-pull converter in island mode, without the need of additional energy storage systems, such as batteries and supercapacitors. The microinverter delivers the energy demanded by the load if enough energy is available from the PV panel. It is worth pointing out that batteries are the typical backup energy system used in island mode (also in stand-alone) inverters to maintain the supply capacity during at least several minutes, even several hours, when the input source fails. Certainly, the DC-link capacitors of the power stage are charged at $1 / 2 \cdot C \cdot V^{2}$, being 'microinverter built-in' energy storage devices. However, for the usual values of $C$ in this kind of systems the amount of energy stored in those capacitors is relatively low, so that they can't be considered a backup energy storage device. As an exception, if batteries are combined with the use of supercapacitors, the latter could be considered as a part of the backup energy storage.

In island mode photovoltaic generation systems usually need backup energy storage to be capable of simultaneously regulating the ac voltage at the point of common coupling and of managing efficiently the PV source. With the proposed operation the microinverter can perform both functions at the same time without the need of an energy backup. That constitutes an important contribution of this paper.

The paper is organized as follows. First, the circuit configuration will be presented. Second, the push-pull circuit will be modeled in order to obtain the transfer functions needed to design the control loops. Third, push-pull controllers in island mode will be designed. Fourth, the controllers will be validated by $\mathrm{PSIM}^{\mathrm{TM}}$ [7] simulation. Finally, some conclusions will be outlined.

\section{Circuit configuration}

The topology selected to develop the microinverter is based on a double conversion scheme. The energy generated from a low power array of panels $(430 \mathrm{~W})$ at low voltage $(24 \mathrm{~V}-37.6$ $\mathrm{V}$ ) is processed by a DC/DC push-pull converter which supplies a $400 \mathrm{Vdc}$ voltage to the power inverter. The circuit scheme of the microinverter is shown in Figure 1.

Fig. 1. Block diagram of the microinverter.

However in the following study, the inverter has been considered as a load from the DC-DC converter point of view. It is quite obvious that the true load is connected at the ac side of the microinverter, but the inverter stage is the front-end of the DC-DC converter, so that modeling the inverter as a load for the DC-DC converter is quite reasonable. This scheme is presented in Figure 2.

Fig. 2. Gonventionat-Proposed peak current control scheme of push-pull converter. NOTA: No entiendo por qué se la llama 'conventional' cuando en realidad es lo que se propone, y por tanto debería ser 'proposed'

In the isolated operation mode and without the use of backup energy storage elements, the push-pull should deliver the amount of energy demanded by the load if the generation 
capacity is not exceeded. In that case the supplied power should be limited to the maximum available from the source. To achieve this, this paper proposes to regulate the input voltage $\left(V_{g}\right)$ of the push-pull by means of a reference set by the addition of two components. The first one is the signal calculated by the maximum power point tracker, MPPT ( $\left.V_{\text {ref-MPPT }}\right)$, implemented by a P\&O (perturb and observe) algorithm [8-10]. The second component is obtained by closing an external voltage loop, which controls the output voltage $\left(V_{D C}\right)$ of the push-pull, i.e., the input voltage of the inverter. Note that this voltage is usually controlled by the inverter in grid connected applications, because there is no need to regulate the ac voltage and, therefore, the inverter can regulate its input dc voltage by managing the amount of energy that is injected to the grid. On the contrary, in island mode the inverter must regulate the ac voltage, so that it can't also regulate its input dc voltage. Apparently, the DCDC converter could achieve this task in a conventional way, i.e., by closing a voltage control loop of the output voltage around the inner current loop. However, in that case the PV panels voltage would be uncontrolled and the energy that they are supplying would not be efficiently managed, i.e. the maximum power point (MPP) wouldn't be reached. With the proposed approach, the push-pull converter is regulating simultaneously both the output and the input voltages. The input voltage is controlled by closing a control loop around the inner current loop, while the output voltage is regulated by means of the proposed additional control loop.

The current controller was implemented using peak current control $(\mathrm{CIC})$ [11], because in the push- pull and other isolated DC-DC converters a small difference between the switching times of the transistors may cause imbalance in the volts-seconds applied to the transformer, producing its saturation and dangerous overcurrents through the transistors. Those overcurrents are naturally avoided by $\mathrm{CIC}$.

It is worth to point out that there is an inherent limitation given by the maximum power that can be provided by the renewable source. If the consumed power is lower than the generated one, it is necessary to leave the maximum power imposed by the MPPT to handle such loads. In the opposite case (generation lower than consumption), the system cannot meet this demand and the push-pull action is determined by the power management scheme.

Table 1 summarizes the nominal values of the Push-Pull converter under study.

Table 1. Parameters of the Push-pull Under Study

\begin{tabular}{lc}
\hline \multicolumn{1}{c}{ Parameter } & Values \\
\hline Panel voltage variation $\left(\mathrm{V}_{\mathrm{g}}\right)$ & {$[24 \mathrm{~V}-36.7 \mathrm{~V}]$} \\
Injected power by panel $\left(\mathrm{P}_{\mathrm{pv}}\right)$ & $430 \mathrm{~W}$ \\
Output voltage $\left(\mathrm{V}_{\mathrm{DC}}\right)$ & $400 \mathrm{~V}$ \\
Push-pull inductance $\left(\mathrm{L}_{\mathrm{X}}\right)$ & $11 \mathrm{mH}$ \\
Push-pull input capacitor $\left(\mathrm{C}_{\mathrm{IN}}\right)$ & $6.8 \mathrm{mF}$ \\
Push-pull transformer turns ratio $(\mathrm{N})$ & 20 \\
Push-pull switching frequency $\left(\mathrm{f}_{\mathrm{s}}\right)$ & $20 \mathrm{kHz}$ \\
DC link capacitor $\left(\mathrm{C}_{\mathrm{DC} \text { LINK }}\right)$ & $1 \mathrm{mF}$ \\
\hline
\end{tabular}

\section{5}

146

147

148

149

150

151

152

153

\section{Modelling of the Push-Pull DC-DC converter}

Power converters (DC/DC or DC/AC) are nonlinear circuits; they must be linearized around an operating point in order to apply linear control techniques. The model presented in this paper is based on the PWM switch model [12-13]. This model explains satisfactorily, with results closed enough to reality, the small signal behavior of converters working in both continuous and discontinuous conduction mode. Additionally, it offers a linear equivalent circuit from which it is possible to perform both small signal and DC analysis. 
Fig. 3. Circuital scheme of push-pull.

The current source $I_{p v}$ represents the current generated by the photovoltaic panels and $R_{L O A D}$ represents the load which is fed by the push-pull. Note that $R_{L O A D}$ is used to model the power demanded by the inverter that is feeding the AC loads.

The equivalent circuit of the push-pull at an operating point is shown by Figure 4 .

Fig. 4. Equivalent circuit of the push-pull at an operating point.

From Figure 4 the following relationships can be established:

$$
\begin{aligned}
\mathrm{I}_{\mathrm{L}} & =\frac{V_{D C}}{R_{\mathrm{LOAD}}} \\
V_{D C} & =\mathrm{D}^{\prime} \cdot \mathrm{k} \cdot \mathrm{V}_{\mathrm{g}}
\end{aligned}
$$

The turns ratio is defined as $k=1 / N=\left(N_{S} / N_{P}\right)$, and the effective duty cycle as $D^{\prime}=2 \cdot D$, being $D$ the duty cycle of each one of the switches of the push-pull.

By the linearization around an operation point, a small signal model results as it is shown in Figure 5.

Fig. 5. Small signal model of the push-pull.

As it is shown in figure 5 , the quantities written in lower-case with the symbol "^" mean smallsignal terms. The uppercase quantities are operating point values.

Besides, the panels have been modeled by the linearization of the curves $i_{p v}=i_{p v}\left(v_{g}\right)$ around an operating point near the point of maximum power. The expression that determines the averaged value of the PV panel power, $\bar{P}_{p v}$, defined as the sum of the power in the operating point, $\mathrm{P}_{\mathrm{pv}}$, and the small signal term, $p_{p v}$, is as follows:

$$
\bar{P}_{p v}=P_{p v}+\hat{p}_{p v}=P_{p v}+V_{g} \cdot \hat{i}_{p v}+\hat{v}_{g} \cdot I_{p v}+\hat{i}_{p v} \cdot \hat{v}_{g}
$$

By neglecting the nonlinear term $\hat{\mathrm{i}}_{\mathrm{pv}} \cdot \hat{v}_{\mathrm{pv}}$ and taking into account that $\hat{p}_{p v}=0$ in an operating point closed to the maximum power point, the following equation is obtained:

$$
\hat{i}_{p v}=-\frac{l_{p v}}{v_{g}} \hat{v}_{g}=m \cdot \hat{v}_{g}
$$

Generally, photovoltaic generators are composed by an array of panels; therefore equation (3) can be rewritten as: 


$$
\hat{\mathrm{i}}_{\mathrm{pv}}=-\frac{\mathrm{n}_{\mathrm{p}}}{\mathrm{n}_{\mathrm{s}}} \frac{\mathrm{l}_{\mathrm{pv}}}{\mathrm{v}_{\mathrm{g}}} \mathrm{v}_{\mathrm{g}}=\mathrm{m} \cdot \hat{v_{g}}
$$

Where $n_{p}$ is the number of branches in parallel and $n_{s}$ is the number of panels connected in series per branch.

\section{Push-pull control}

As it was outlined in the previous section, peak current control $(\mathrm{CIC})$ has been chosen to control the peak current in the active switches (power transistors), so that there is an inherent protection to overcurrents. The reference of the current loop is set by the controller of the $V_{g}$ voltage loop, i.e., the voltage applied to the photovoltaic panels. As explained in section 2, the reference of the panels voltage control loop is set by the combined action of the MPPT and the $V_{D C}$ voltage controller. Figure 6 shows the block diagram that represents the system.

Fig. 6. Push-pull Control loops of input voltage, current and output voltage.

The power stage open loop transfer functions from the duty cycle to the output voltage $\left(G_{V D C}\right.$ $d(s))$, from the duty cycle to the input voltage $\left(G_{V g-d}(s)\right)$ and from the duty cycle to the output inductor current $\left(G_{i L x-d}(s)\right)$ can be extracted from the dynamic models depicted in Figure 3 and Figure 4. The transfer function $\mathrm{G}_{\mathrm{VDC}-\mathrm{d}}(\mathrm{s})$ is expressed as: OJO: la figura 3 no es un modelo de pequeña señal. Igual es otra figura.

$$
G_{V D C-d}(s)=\left.\frac{\hat{V}_{D C}}{\hat{d}}\right|_{i_{0}=0}=\frac{Z_{e q} \cdot\left(2 \cdot k^{2} \cdot D^{\prime} \cdot L_{L x}+2 \cdot k \cdot V_{g} \cdot\left(m-s \cdot C_{I N}\right)\right)}{-k^{2} \cdot D^{\prime 2}+\left(s \cdot L_{x}+Z_{e q}\right) \cdot\left(m-s \cdot C_{I N}\right)}
$$

Where $Z_{e q}$ is the impedance observed after the inductor $t_{L_{x}} L_{x}$ Supongo que será $L x$ (el inductor, no la corriente) and it is expressed following (6).

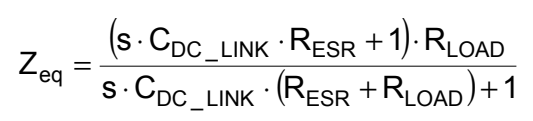

The transfer function $G_{V g-d}(s)$ is expressed as follows:

$$
G_{V g-d}(s)=\left.\frac{\hat{V}_{g}}{\hat{d}}\right|_{\hat{V}_{D C}=0}=-\frac{\left(2 \cdot V_{g} \cdot k \cdot D^{\prime}+s \cdot 2 \cdot I_{L x} \cdot L_{x}\right) \cdot k}{k^{2} \cdot D^{\prime 2}-s \cdot L_{x} \cdot m+s^{2} \cdot L_{x} \cdot C_{I N}}
$$

The expression of the third transfer function is the following:

$$
G_{i L x-d}(s)=\left.\frac{\hat{i_{L x}}}{\hat{d}}\right|_{\hat{i}_{0}=0}=\frac{2 \cdot k^{2} \cdot D^{\prime} \cdot I_{L x}+2 \cdot k \cdot V_{g} \cdot\left(m-s \cdot C_{I N}\right)}{-k^{2} \cdot D^{\prime 2}+\left(s \cdot L_{x}+Z_{e q}\right) \cdot\left(m-s \cdot C_{I N}\right)}
$$

\subsection{Design of the inner current control loop}

After obtaining these transfer functions, the sampling gain $H_{e}(s)$ [14] can be calculated from the following expression: 
232

$$
H_{e}(s)=\frac{s^{*} T_{S}}{e^{s^{*} T_{s}}-1} \approx 1+\frac{s}{\omega_{Z}{ }^{*} Q_{Z}}+\frac{s^{2}}{\omega_{Z}^{2}}
$$

Where:

$$
\begin{aligned}
& \omega_{Z}=\frac{\pi}{T_{S}}=62831.853 \\
& Q_{Z}=-\frac{2}{\pi}=-0.6366
\end{aligned}
$$

Finally:

$$
H_{e}(s)=0.253 \cdot 10^{-9} \cdot s^{2}-25 \cdot 10^{-6} \cdot s+1
$$

The sampling gain is very important to analyze the current inner loop for stability reasons. It adds to the current loop two complex conjugate non-minimum phase zeros at half the switching frequency [13]. This expression can be approximated to a second order polynomial from DC to half the switching frequency, which is the limit of the small-signal models validity.

A current sensor gain $R_{i}=0.015 \mathrm{~V} / \mathrm{A}$ has been chosen .

The following step is to determine the gain of the PWM modulator $\left(F_{M}\right)$. In the case of CIC, $F_{M}$ depends on the sensing $\operatorname{ramp}\left(S_{n}\right)$ and the slope of the external stabilization $\operatorname{ramp}\left(S_{e}\right)$, which has a constant amplitude and frequency. The goal of this ramp is to stabilize the inner current loop in the whole range of the push-pull duty cycle. $F_{M}$ is expressed by (12).

$$
\begin{gathered}
F_{M}=\frac{1}{\left(S_{n}+S_{e}\right) \cdot T_{s}}=\frac{1}{m_{c} \cdot S_{n} \cdot T_{s}} \\
m_{c}=1+\frac{S_{e}}{S_{n}}
\end{gathered}
$$

Being $m_{c}$ a factor that establishes the level of stabilization provided by the external ramp.

The value of $S_{n}$ is obtained from the following equation:

$$
S_{n}=\frac{k^{2} \cdot\left(1-D^{\prime}\right) \cdot V_{g} \cdot R_{i}}{L x}=2181 \mathrm{~V} / \mathrm{seg}
$$

The next step in the design of CIC is to determine the value of $m_{c}$ for which the current loop is stable. The expression of the current loop gain can be deduced from Figure 6 as: $T_{i}(s)=G_{i L}$ ${ }_{d}(s) \cdot F_{M} \cdot k \cdot R_{i} \cdot H_{e}(s)$. In order to determine the value of $m_{c}$ that makes the current loop stable and physically implementable, it is useful to perform a sweep of $T_{i}(s)$ based on this parameter as it is shown by Figure $7 \mathrm{a}$. In a similar way, Figure $7 \mathrm{~b}$ depicts the Bode plots of the transfer function from the reference voltage to the inductor current as a function of $m_{c}$.

Fig. 7. Bode diagrams of (a) current loop $T_{i}(s)$, and (b) reference voltage to inductor current transfer function, for several values of $m_{c}$.

From figure 7 it can be seen that for $m_{c}$ values above 3 , the system is stable, but the crossover frequency decreases as the value of $m_{c}$ increases. For a value of $m_{c}=15$, a phase margin close to $77.7^{\circ}$ and a crossover frequency of $1.42 \mathrm{kHz}$ results.

\subsection{Design of the panels voltage control loop}


A voltage controller $G_{v}(s)$ must be chosen for cascade compensation of the current control loop. Therefore, it is necessary to keep in mind the voltage sensor gain ( $\beta=0.05$ in this case), and the transfer function from the control voltage to the input voltage of the push-pull converter, $G_{v g-v_{c}}(s)$. This transfer function can be obtained from (7), (8) and the auxiliary function that relates the inductor current and the control signal from the voltage controller, following (14).

276

277

278

279

280

281

282

283

284

285

286

287

288

289

290

291

292

293

294

295

296

297

298

299

$$
G_{i L_{x}-v_{c}}(s)=\frac{\hat{i}_{L x}}{\hat{v}_{C}}=\frac{T_{i}(s)}{R_{i} \cdot\left(1+T_{i}(s)\right)}
$$

The transfer function $G_{v g-v_{c}}(s)$ is expressed as follows:

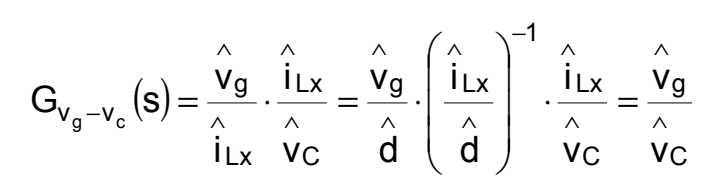

The voltage controller sets the reference signal for the current control loop to regulate the push-pull input voltage; it was implemented by means of a PI controller [15]. The expression of the chosen controller is:

$$
G_{v}(s)=K_{p}+\frac{K_{i}}{s}=3.75+\frac{750}{s}
$$

Figure 8 shows the bode diagram of the voltage loop gain, which is defined as $T_{v}(s)=G_{v g-}$ $v_{c}(s) \cdot \beta \cdot G_{v}(s)$. The diagram shows that the proposed controller achieves a phase margin of $90.2^{\circ}$ and a crossover frequency of $199 \mathrm{~Hz}$. This crossover frequency was selected to be much smaller than the crossover frequency of the current loop, but not too small to slow down the control action.

Fig. 8. Bode diagram of the transfer function of the voltage loop gain $T_{v}(s)$.

\subsection{Design of the external voltage loop for VDC regulation}

In order to design the voltage controller for the regulation of $V_{D C}$, it is necessary to obtain the control to output transfer function $G_{V g-v r e f}(s)$, and the transfer function from the PV voltage to the voltage $V_{D C}, G_{V D C-V g}(s)$. These transfer functions are presented below, following (17) and (18):

$$
G_{v_{g}-v_{\text {ref }}}(s)=\frac{G_{V}(s) \cdot G_{v_{g}-v_{c}}(s)}{1+G_{V}(s) \cdot G_{v_{g}-v_{c}}(s) \cdot \beta}
$$

$$
G_{V_{D C}-v_{g}}(s)=\frac{\hat{V}_{D C}}{\hat{d}} \cdot\left(\frac{\hat{v}_{g}}{\hat{d}}\right)^{-1}=\frac{k \cdot Z_{e q} \cdot\left(2 \cdot D^{\prime} \cdot k \cdot I_{L X}+2 \cdot V_{g} \cdot\left(m-s \cdot C_{I N}\right)\right)}{2 \cdot k^{2} \cdot D^{\prime} \cdot V_{g} \cdot+\left(s \cdot L_{x}+Z_{e q}\right) \cdot 2 \cdot k \cdot I_{L X}}
$$

A value of $\alpha=0.006$ has been chosen as sensing gain of $V_{D C}$. To achieve the desired performance, the controller $G_{V D C}(s)$ was implemented by means of a PI controller in cascade with an integrator, following (19). 


$$
\mathrm{G}_{V D C}(\mathrm{~s})=-\frac{1}{\mathrm{~s}} \cdot\left(\mathrm{K}_{\mathrm{p}}+\frac{\mathrm{K}_{\mathrm{i}}}{\mathrm{s}}\right)=-\frac{1}{\mathrm{~s}} \cdot\left(30299+\frac{5756.81}{\mathrm{~s}}\right)
$$

Figure 9 shows the bode diagram of the $V_{D C}$ voltage loop gain, $T_{V D C}(s)=G_{V D C \text {-vref }}(s)$ $\cdot \alpha \cdot G_{V D C}(s)$. Where the transfer function $G_{V D C-v r e f}(s)$ may be calculated as:

$$
G_{V D C-v_{\text {ref }}}(s)=\frac{\hat{V}_{D C}}{\hat{v}_{g}} \cdot \frac{\hat{v}_{g}}{\hat{V}_{r e f}}
$$

Fig. 9. Bode diagram of the transfer function of the $V_{D C}$ voltage loop gain, $T_{V D C}(s)$.

In Figure 9, the crossover frequency is $50 \mathrm{~Hz}$ and the phase margin is $76.2^{\circ}$. This figure shows that the the system is stable for a given operating point (output power: $430 \mathrm{~W}$ and PV voltage at the MPP: $29.25 \mathrm{~V}$ ). However, it is necessary to analyze different operating points as a function of the load power demand. Note that if the power demand is lower than the MPP power, it is possible that the same PV power can be delivered at two different operating points of the panel P-V curve (i.e. at two different values of the panel voltage), at it is shown in Figure 10.

Fig. 10. Panel power vs. voltage. Marcar una horizontal de "load power demand" por debajo del MPP y dos tensiones de panel Vg1 y Vg2 para visualizar en concepto anterior. Marcar que el punto de trabajo correcto es a la derecha del MPP "correct operation point".

In the Figure 10 it is shown the panel power vs. voltage for $1000 \mathrm{w} / \mathrm{m}^{2}$ irradiance. Additionally, the control zones where the push-pull operates are shown.

Figure 11.a shows a parametric sweep of the $D C$ voltage loop $T_{V D C}(s)$ and the Figure 11.b shows a parametric sweep transfer function $V_{D C}$ vs. the reference voltage, $G_{V D C-V r e f} V D C(s)$, depending on the power consumed by the load and associated input voltage to the push-pull, according to the values presented in Figure 10.

Fig. 11. Parametric sweep of (a) $T_{V D C}(s)$, and (b) $G_{V D C-V r e f V D C}(s)$, depending on the power consumed by the load and associated input voltage to the push-pull.

It can be observed that when the panel voltage is low (less than $21 \mathrm{~V}$ ) the system becomes unstable. The reason for this phenomenon is that the duty cycle is close to 1 , so that the system is not able to regulate the load condition. Therefore, in order to supply low power loads the push-pull should work at the right side of the MPP, as shown by Figure 10. A major challenge is to determine the maximum power that can be delivered by the panel without using temperature and irradiance sensors, thus reducing implementation costs.

A solution to this problem is to place a negative limiter. The solution is based on the following: if the power consumption is lower than the generated one, the reference voltage will be lower than the sensed value of $\mathrm{V}_{\mathrm{DC}}$, so that the error is negative. The negative value of the error is multiplied by the negative gain of the controller. This results in a positive value of the control action that is added to the reference set by the MPPT, so that the panel voltage increases, delivering the lower power consumed by the load. Additionally, the push-pull regulates the voltage $V_{D C}$. If the error is positive $\left(V_{D C}\right.$ ref $\left.>V_{D C}\right)$, amplifying by the negative gain of the voltage controller yields a negative value that becomes zero at the output of the limiter, 
so that the PV panel voltage follows the reference of the MPPT algorithm, that will extract the maximum power available from the energy source.

Any real controller has a saturation region, and this region added to the integral effect of the $\mathrm{PI}$ produces a phenomenon called reset-windup [16]. This phenomenon can cause overshoots in the time response and it can even destabilize the system. However, such a phenomenon only appears when there are significant changes in the reference signal or large-scale disturbances like abrupt load steps above $60 \%$. A mechanism to address the phenomenon described above is included in the control loop as an anti-windup. This mechanism allows saturating the integral term to a preset value, in order to avoid extremely large control actions from the controller [17]. These techniques can be classified by two different approaches, conditional integration and back calculation [18]. The back calculation [19] uses the difference between the saturated control signal and the unsaturated control signal to generate a feedback signal that acts on the integrator input. The idea is to calculate the integral action so that the new value does not reach the saturation level. This technique was implemented in this paper.

\section{Simulation Results}

This section presents a simulation study about the operation of the push-pull converter working in island mode. The simulations were carried out by PSIM $^{\text {TM }}$ software and the scheme of the push-pull converter that was presented in Section II.

Figure 12 depicts the response of the most important electrical variables (output voltage, input voltage, input current and output power) of the push-pull to a load variation from $150 \mathrm{~W}$ to $410 \mathrm{~W}$ when the power that can be extracted from the panels is enough to meet the load power demand. Note that the maximum irradiance $\left(1000 \mathrm{~W} / \mathrm{m}^{2}\right)$ was taken, so that the system can deliver full power $\left(430 \mathrm{~W}\right.$ at $\left.\mathrm{V}_{\mathrm{DC}}=29.25 \mathrm{~V}\right)$.

Fig. 12. Main waveforms of voltage, current and power of the push-pull for changes in the load power demand when the demand is lower than the generated power.

Figure 12 shows that the system responds to load changes ( $340 \mathrm{~W}, 410 \mathrm{~W}$ and $150 \mathrm{~W}$ ), following properly the power reference. It is observed that the panel voltage is greater than the voltage at the MPP (29.25 V), because the load power consumption is lower than the MPP of the PV source.

Figure 13 shows the control signals imposed by the MPPT $\left(V_{M P P T}\right)$ algorithm, the push-pull output voltage controller $\left(V_{P I D C}\right)$ and the voltage reference imposed to the push-pull input voltage controller $\left(V_{\text {ref }}\right)$ for the load demand changes of Figure 12. No está claro si $V_{M P P T}$ es la señal a la salida del algoritmo MPPT o la suma de ésta con la salida del limitador negativo. Explicarlo!! Sería buena añadir las etiquetas correspondientes a la figura 2. Por cierto: la señal $V_{\text {ref }}$ en la figura 2 que yo tengo no es una referencia sino una señal de error. Comprobar las etiquetas de la figura 2!!!!

Fig. 13. Control signals associated to the voltage reference imposed to the input voltage controller.

Note that the reference voltage of the input voltage controller, $V_{\text {ref, }}$, is the sum of the reference

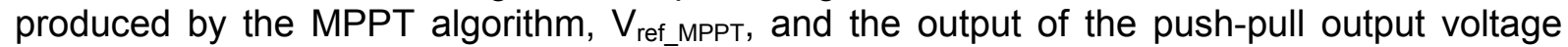
controller affected by the negative limiter, $V_{\text {PIDC }}$ (see Figure 2). Additionally, Figure 13 shows how the output voltage controller takes over the system control while the signal imposed by the MPPT decreases. 
Figure 14 shows the system response to load power demand changes from $420 \mathrm{~W}$ to $440 \mathrm{~W}$, exceeding in some time intervals the power that the photovoltaic panels array can generate $(430 \mathrm{~W})$.

Fig. 14. Main waveforms of voltage, current and power of the push-pull at power demand changes exceeding the generated PV power in some time intervals.

Figure 14 shows that when the power demand exceeds the generation (changing from 420 $\mathrm{W}$ to $440 \mathrm{~W}$ at $\mathrm{t}=1.3 \mathrm{~s}$ ), the system is able to deliver the maximum power available in the panels $(430 \mathrm{~W})$; this is due to the effect of keeping the MPPT algorithm operating. In addition, due to the negative limiter, the $V_{D C}$ voltage controller does not correct the reference value of the voltage set by the MPPT, which reduces the voltage $V_{D C}\left(V_{D C}\right.$ keeps below $\left.V_{D C_{-} \text {ref }}\right)$. By changing the load from $440 \mathrm{~W}$ to $420 \mathrm{~W}$ at $t=5 \mathrm{~s}$, and because the system is within the range to supply the load demand, it regulates the voltage back to $400 \mathrm{~V}$ and meets the power requirements of the load.

It is worth pointing out that when the overload phenomenon happens the system reduces the voltage $V_{D C}$, so that it is necessary to define a lower value for which the system stops working, or just left it in standby status, as defined by the microgrid management system.

Figure 15 shows the control signals imposed by the MPPT $\left(V_{M P P T}\right)$, the push-pull output voltage controller $\left(V_{P I D C}\right)$ and the voltage reference imposed to the push-pull input voltage controller $\left(V_{\text {ref }}\right)$ when the overloading phenomenon happens.

Fig. 15. Control signals associated to the voltage reference imposed to the input voltage controller when the overloading phenomenon happens.

Figure 15 shows that when the overload occurs from $t=1.3 \mathrm{~s}$ to $5 \mathrm{~s}$, the signal imposed by input voltage controller is only determined by the MPPT, while the response of the output voltage controller is cancelled by the limiter.

\section{Conclusion}

This paper presents the modeling and control of a push-pull converter operating in island mode fed by photovoltaic panels. A small signal model of the converter is obtained, starting from which all transfer functions of interest for the design of the control loops have been calculated. An innovative control scheme has been proposed to achieve a proper power balance at the load without the need of using backup energy storage elements.

As a result, the generated power is reduced to match the load power demand, both when the demand is lower than the maximum one that can be extracted from the PV panels, and when the power consumption exceeds the generated one. Obviously, in the first case the output voltage is reduced leaving the MPP of the PV source, so that both the generated and the supplied power agree. In the second case the power delivered to the load agrees with the MPP of the source. The controllers design and the operation of the push-pull converter are validated by means of $\mathrm{PSIM}^{\mathrm{TM}}$ simulations.

\section{Acknowledgements}

This work was supported by the Spanish Ministry of Science and Innovation under Grant ENE2009-13998-C02-02. 


\section{References}

455

456

457

458

459

460

461

462

463

464

465

466

467

468

469

470

471

472

473

474

475

476

477

478

479

480

481

482

483

484

485

486

487

488

489

490

491

492

493

494

495

496

497

[1] Y. Ruan, Q. Liu, W. Zhou, R. Firestone, W. Gao, T. Watanabe, Optimal option of distributed generation technologies for various commercial buildings, Applied Energy 2009; 86: 1641-1653.

[2] P. Mancarella, G. Chicco, Global and local emission impact assessment of distributed cogeneration systems with partial-loads models, Applied Energy 2009; 86: 2096-2106.

[3] G.C. Bakos, Distributed porwer generation: A case study of small scale PV power plant in Greece, Applied Energy 2009; 86: 1757-1766.

[4] R.W. Erickson, A.P. Rogers, A Microinverter for Building-Integrated Photovoltaics, IEEE Applied Power Electronics Conference and Exposition, 2009; 1: 911-917.

[5] M. Calais, J. Myrzik, T. Spooner, V.G. Agelidis, "Inverters for single-phase grid connected photovoltaic systems-an overview, IEEE Power Electronics Specialists Conference, 2002; 4: 1995-2000.

[6] F. Kang, S. Park, J. Kim, Photovoltaic power interface circuit incorporated with a buck-boost converter and a full-bridge inverter, Applied Energy 2005; 82: 266-283.

[7] PSIM 7.0 User's Guide (2006), Powersim Inc.

[8] T. Esram, P.L. Chapman, Comparison of Photovoltaic Array Maximum Power Point Tracking Techniques, IEEE Trans. on Energy Conversion, 2007; 22: 439-449.

[9] I.S. Kim, Sliding mode controller for the single-phase grid-connected photovoltaic system, Applied Energy 2006; 83: 1101-1115.

[10] L.G. Gonzalez, E. Figueres, G. Garcerá, O. Carranza, Maximum-power-point tracking with reduced mechanical stress applied to wind-energy-conversion systems, Applied Energy, 2010; 87 2304-2312.

[11] D.M. Sable, R.B. Ridley, Comparison of performance of single-loop and current-injection control for PWM converters that operate in both continuous and discontinuous modes of operation, IEEE Trans. on Power Electronics, 1992; 7: 136-142.

[12] V. Vorperian, Simplified analysis of PWM converters using model of PWM switch. Continuous conduction mode, IEEE Trans. on Aerospace and Electronic Systems, 1990; 26: 490-496.

[13] D.M. Sable, R.B. Ridley, B.H. Cho, Comparison of performance of single-loop and currentinjection control for PWM converters that operate in both continuous and discontinuous modes of operation, IEEE Trans. on Power Electronics, 1992; 7: 136-142.

[14] R. B. Ridley, A new, continuous-time model for current-mode control (power convertors), IEEE Trans. on Power Electronics, 1991; 6: 271-280.

[15] B.C. Kuo, F.Golnaraghi, Automatic control systems, John Wiley \& Sons, 2002.

[16] Jong-Koo Park, Chong-Ho Choi, Dynamic compensation method for multivariable control systems with saturating actuators, Automatic Control, IEEE Transactions on, 1995; 40: 1635-1640.

[17] Jong-Woo Choi, Sang-Cheol Lee, Antiwindup Strategy for PI-Type Speed Controller, IEEE Trans. on Industrial Electronics, 2009; 56: 2039-2046.

[18] K. J. Åström, T. Hägglund, PID Controllers: Theory, Design, and Tuning. Research Triangle Park, NC: ISA, Jan. 1995.

[19] K. Ohishi, E. Hayasaka, T. Nagano, M. Harakawa, T. Kanmachi, High-performance speed servo system considering Voltage saturation of a vector-controlled induction motor, IEEE Trans. on Industrial Electronics, 2006; 53: 795- 802. 